\title{
“ESTAR INTERNADA É FICAR O DIA TODO PRESA": 0 COTIDIANO NO FALATÓRIO AUTOBIOGRÁFICO DE STELA DO PATROCINIO
}

\author{
Viviane Trindade Borges'
}

Resumo: Este artigo é sobre uma paciente da Colônia Juliano Moreira, cuja singularidade e poesia ganharam destaque em âmbito nacional. Refiro-me a Stela do Patrocínio. Seu falatório autobiográfico foi cuidadosamente registrado entre 1986 e 1989 e já inspirou exposições, canções e peças de teatro. Através da análise de tais fontes, objetivo problematizar a imagem tecida pela personagem a respeito da instituição onde viveu por cerca de trinta anos. Em sua fala a vida cotidiana na instituição é desenhada como um modo de existência em que o indivíduo cria relações na base de sua própria possibilidade de ação. Stela não se calou, jogou com sua única possibilidade de ação diante dos limites institucionais: a sua fala, permeada por perplexidade, indignação e sem dúvida, muita lucidez.

Palavras-chave: Cotidiano; Autobiografia; Loucura; Psiquiatria; Stela do Patrocínio

\begin{abstract}
This article aims to analyze the speech of a patient in the Juliano Moreira Colony, whose uniqueness and poetry gained prominence on the national level. I refer to Stela. His speech was carefully recorded between 1986 and 1989 and has inspired exhibitions, theater shows and songs. Through the analysis of such sources, to analyze the vision of Stela about the institution where he lived for about thirty years. In his speech to life in the institution is brought to light as a mode of existence in which the individual creates relationships based on their own possibility of action. Stela is not silent, played with their only chance of action before the institutional boundaries: his speech, permeated by astonishment, indignation, and without doubt, very clear.
\end{abstract}

Keywords: Everyday Life; Autobiography; Madness; Psychiatry; Stela do Patrocínio

I Mestre e Doutora em História pela UFRGS, professora do epartamento de História da UDESC. 


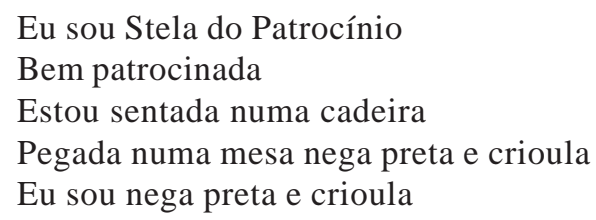

Nega, preta e crioula, assim se definia Stela do Patrocínio. A personagem foi internada pela primeira vez em 1962, no Centro Psiquiátrico Pedro II, no Rio de Janeiro, aos 21 anos, sob o diagnóstico de "personalidade psicopática mais esquizofrenia hebefrenica, evoluindo sob reações psicóticas”. Foi transferida em 1966 para a Colônia Juliano Moreira. Nesta última instituição Stela permaneceu por quase trinta anos, sem receber uma única visita. Morreu em 1992, devido a uma infecção generalizada, contraída após a amputação de uma de suas pernas em virtude de uma hiperglicemia grave. Apesar dos esforços realizados pela instituição, seus parentes nunca foram localizados.

A idéia de escrever um artigo a respeito de Stela do Patrocínio surgiu em 2006, em função de uma pesquisa realizada na Colônia Juliano Moreira² ${ }^{2}$ Lá, foi possível conhecer os ditos de Stela, presentes na biblioteca que leva seu nome, dentro do espaço institucional. O presente estudo busca problematizar a maneira como a personagem desenhou o cotidiano asilar, entrelaçando este a sua memória autobiográfica. Perpassando alguns temas recorrentes em sua fala, é possível perceber a instituição de determinada visão a respeito dos 30 anos de internamento na Colônia Juliano Moreira.

A exemplo das muitas histórias anônimas que atravessaram os manicômios através dos séculos, pouco se sabe a respeito de Stela. Ela teria nascido em 9 de janeiro de 1941, filha de Manoel do Patrocínio e Zilda Xavier do Patrocínio, contava que era solteira:

doméstica, de instrução secundária. Que morava (o que não foi confirmado) na Rua Maria Eugenia 50, apto 501, Botafogo. Que tinha como familiar responsável o sobrinho, Reinaldo do Patrocínio, cujo endereço, Estrada da Gávea 460, Rocinha, não pode ser confirmado. Que este sobrinho a visitou um tempo e depois desapareceu. Que dizia ter duas irmãs, Ruth e Olívia, já falecidas, e um cunhado, marido de Olívia e pai de três sobrinhos: Reinaldo, Cosme e Eduardo. Que a mãe já foi interna do Núcleo Teixeira Brandão e conseguiu sair antes que ela desse entrada naquele hospital. Que era domestica na Urca, na mesma casa em que a mãe enlouqueceu ${ }^{3}$

Os dados biográficos lacunares e imprecisos não foram confirmados por Stela. O que dela permaneceu foi seu falatório, preenchido por uma vitalidade e força intensas. O falatório de Stela foi transcrito a partir de gravações 
"Estar internada é ficar o dia todo presa": o cotidiano no falatório autobiográfico de Stela do 141 Patrocínio

realizadas entre 1986 e 1989, por iniciativa de voluntários, como a artista plástica Neli Gutmacher, na época professora da Escola de Artes Visuais do Parque da Lage, que a convite da psicóloga Denise Corrêa, montou um ateliê dentro da Colônia Juliano Moreira. A idéia de gravar a fala de Stella ocorreu em virtude das preferências da própria personagem, a qual optava usar a fala para se expressar ou invés de desenhos:

Apesar de freqüentar o ateliê, raramente utilizava os materiais propostos. Quando desenhava, o que era raro, eram coisas quase minimalistas, expressões pequenas, muito próximas à escrita. Algumas vezes escrevia em papelão,frases ou números. Mas o que realmente diferenciou Stela no grupo foi a sua fala. Ao contrário das outras internas, que aceitavam se relacionar com tinta e papéis, ela preferia a palavra. E parecia ter clareza desta preferência. Em sua fala desconcertante, incisiva, cada sílaba era pronunciada com gosto ${ }^{4}$.

Sua voz extravasou o espaço institucional em 1988, na exposição intitulada “Ar subterrâneo", realizada no Paço Imperial no Rio de Janeiro. Na mostra, trechos de sua fala foram transcritos em pedaços de papelão. A partir deste trabalho o músico Cabelo passou a utilizar fragmentos de seus textos nos shows do grupo Boato.

Em 2001 seus textos foram adaptados para o teatro na peça "Stela do Patrocínio óculos, vestido azul, sapato preto, bolsa branca e ... doida”. Neste mesmo ano a fala de Stela virou livro, "Stela do Patrocínio - Reino dos bichos e dos animais é meu nome”, organizado pela socióloga Viviane Mosé (2001)5. Nele encontram-se transcritos parte do material gravado pelo ateliê, ou seja, Stela e seu falatório, o qual serve de fonte para o presente estudo.

As gravações permitiram que a personagem encontrasse uma escuta:

Tenho muito assunto muito falatório

Não encontro ninguém para quem eu possa conversar

Quando não tenho uma voz mais

Não tenho falatório

Uma voz mais

Vocês aparecem

E querem conversar conversar

Cabe salientar que a fala de Stela foi transformada em escrita. Assim, não foi ela quem escreveu os textos aqui citados e jamais saberemos como teria os escrito. Estes foram transcritos e selecionados por Viviane Mosé, organizadora do referido livro, em função da conexão e encadeamento de assunto estabelecido entre eles. Transpor a fala para a escrita não é reproduzir o que foi dito, pois a 
escrita não consegue apreender a fala em sua musicalidade e minúcias próprias. Assim, os textos transcritos resignificam a fala de Stela, instituem um hiato intransponível que não nos permite chegar a sua fala, mas somente a um possível efeito daquilo que Stela quis dizer. Ciente de tais limitações pretende-se aqui percorrer o falatório de Stela.

\section{O COTIDIANO DA COLÔNIA JULIANO MOREIRA NO FALATÓ- RIO DE STELA}

A vida cotidiana é aqui pensada uma maneira de existir na qual o sujeito estabelece relações conforme suas possibilidades de ação ${ }^{6}$. O cotidiano descrito no falatório de Stela não é aqui percebido como um simples pano de fundo, ou cenário pronto onde atuou a personagem em questão, mas como limite e origem de sua construção autobiográfica. Problematizando as imagens por ela instituídas a respeito da instituição na qual viveu, pretende-se vislumbrar o mosaico de sentidos por ela cuidadosamente elaborados, o qual desenha as práticas psiquiátricas nas décadas de 60, 70 e início dos anos 80, imbricadas no cotidiano de um nosocômio localizado no Rio de janeiro.

Conforme Petersen ${ }^{7}$ :

a preocupação de incorporar ao trabalho do historiador a perspectiva do cotidiano significa um enriquecimento analítico indiscutível, já que a presença desta dimensão universal em todo o modo de existência humana certamente relativiza, na analise histórica, o peso do reducionismo estrutural, institucional, objetivista, permitindo reconstruir de forma mais completa e matizada o espaço e o tempo das práticas sociais.

A fala de Stela atuou como um murmúrio contínuo dentro do silêncio penoso da instituição. A tessitura autobiográfica criada pela personagem institui percepções a respeito de si que se entrelaçam ao espaço institucional. Sob esta perspectiva, propõe-se a partir de agora percorrer alguns temas recorrentes em seu falatório encontrando a Colônia Juliano Moreira na fala de Stela.

\section{“E SUMIU DE REPENTE DESAPARECEU DO MUNDO": MESMI- CE, UNIFORMIDADE, REMÉDIOS E SOLIDÃO}

Ao ser questionada sobre como era o seu dia a dia na instituição Stela respondeu:

Segunda terça quarta quinta sexta e sábado

Domingo

Janeiro fevereiro março abril maio junho julho

Agosto setembro outubro novembro dezembro 


\author{
Dia tarde noite \\ Eu fico pastando à vontade \\ Fico pastando no pasto à vontade que nem \\ Cavalo
}

Muitos internados se entregavam a mesmice do cotidiano institucional, vivendo sua apatia, seus dias sempre iguais. Sobre isso Stela relatou:
Aqui no hospital ninguém pensa
Não tem nenhum que pense
Eles vivem sem pensar
Comem bebem fumam
No dia seguinte querem saber
De recontinuar o dia que passou
Mas não tem ninguém que pense
E trabalhe pela inteligência

O cotidiano da Colônia Juliano Moreira, retratado no documentário “O prisioneiro da passagem”, de Hugo Denizart ${ }^{8}$, evidencia este eterno "recontinuar” a que se refere Stela. Esquecidos, amontoados, anônimos. São muitos rostos sem expressão, mulheres que "ninam” bonecas, homens que caminham sem rumo, com os olhos fixos num horizonte sem perspectivas, sempre "recontinuando" "o dia que passou”.

O azul do uniforme institucional tornava tudo mais impessoal. Stela revela que havia aqueles que se vestiam e se calçavam igual a ela, "mas que são diferentes da diferença entre nós”:

$$
\begin{aligned}
& \text { Eu sou seguida acompanhada imitada } \\
& \text { Assemelhada } \\
& \text { Tomada conta fiscalizada examinada revistada } \\
& \text { Tem esses que são igualzinhos a mim } \\
& \text { Tem esses que se vestem e se calçam igual a mim } \\
& \text { Mas que são diferentes da diferença entre nós } \\
& \text { É tudo bom e nada presta. }
\end{aligned}
$$

Stela parece criticar a inibição da subjetividade que permeava a assistência psiquiátrica no período em que ela viveu no Hospício. Sua fala se dirige a psiquiatria, ao tratamento e ao descaso. Em seu falatório, afirma que os remédios lhe faziam mal: 
E se eu levo um tombo eu levanto

Ando mais um pouquinho, torno a cair.

Conforme colocado anteriormente, nos 30 anos de internamento Stela não recebeu uma única visita e, a despeito das tentativas da equipe médica, sua família nunca foi localizada. Apesar de alguns pesquisadores afirmarem que Stela contava que um sobrinho a visitava no inicio do internamento, tal informação nunca foi confirmada. A ausência da família é um tema que perpassa sua narrativa de diferentes formas:

Você nasce sempre

Tem seus herdeiros e seus hereditários todinhos

Tem sua família

Eu não tenho mais família

Minha família toda já morreu

To na família do cientista

A personagem parece se referir aos psiquiatras ao dizer que pertence a "família do cientista”, como neste outro trecho:

Uma família é uma reunião uma reunião

Uma família pra mim é uma reunião de médicos e cientistas

Minha família era a família que se garantia

E sumiu de repente desapareceu do mudou

Stela tinha consciência de seu abandono, ressaltando sua condição de "indigente”: "me trouxeram pra cá como indigente, sem família, vim pra cá, estou aqui como indigente, sem ter família nenhuma, morando no hospital, estou aqui como indigente, sem ter ninguém por mim, sem ter família e morando no hospital”.

\section{“ESTAR INTERNADA É FICAR O DIA TODO PRESA”}

O olhar de Stela a respeito da vida e do internamento é de extremo realismo e perplexidade. Ela define da seguinte forma sua condição de internada:

Estar internada é ficar o dia todo presa

Eu não posso sair, não deixam eu passar pelo portão

Maria do Socorro não deixa eu passar pelo portão

Seu Nelson também não deixa eu passar lá no portão

Eu estou aqui há vinte e cinco anos ou mais

Presa, sem poder atravessar o portão que separa a sociedade tida normal daqueles tidos como loucos, era assim que se colocava Stela em muitos momentos. Maria do Socorro e seu Nelson talvez aqui representem todos os funcionários da Colônia, responsáveis pelos internados, os quais não os deixavam "passar pelo portão". 
Para Stela o hospital poderia por vezes parecer, se assemelhar a um lar, um lugar para si, mas ela sabia: "o hospital é um hospital”:

\author{
Eu estava com saúde \\ Adoeci \\ Eu não ia adoecer sozinha não \\ Mas eu estava com saúde \\ Estava com \\ muita saúde \\ Me adoeceram \\ Me internaram no hospital \\ E me deixaram internada \\ E agora eu vivo no hospital como doente \\ O hospital parece uma casa \\ O hospital é um hospital
}

No falatório de Stela a Colônia Juliano Moreira é o lugar onde a "deixaram internada”. É possível detectar a tessitura de sua condição de doente: "me adoeceram”, acusa Stela; bem como a instituição de um lugar, a Colônia Juliano Moreira, o hospital que por vezes pode parecer sua casa, mas que não deixa de ser hospital, com suas proibições a saídas, uniformes e remédios.

Conforme a personagem: "Eu estou num asilo de velhos / Num hospital de tudo que é doença / Num hospício, lugar de maluco doido”. A loucura é perpassa sua fala de forma questionadora, sôfrega, assumida, refutada, ou orgulhosa, mas sempre presente, sob diferentes nuances.

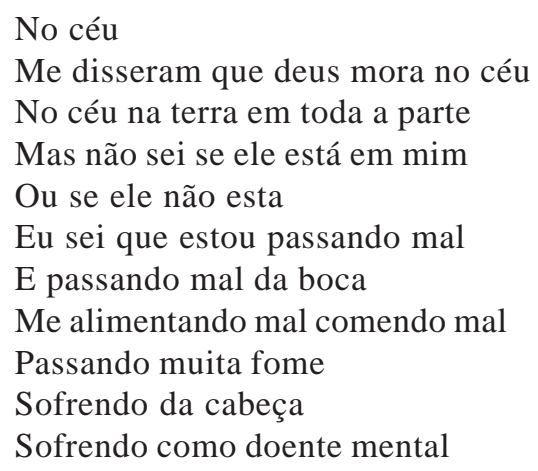

A loucura aqui é questionadora, inquire Deus em seus desígnios, mas também é sôfrega, é doença que causa sofrimento. De forma contraditória, em outros momentos, essa mesma loucura retratada como sofrimento é tecida como um troféu, mostrando-se orgulhosa, como algo a ser invejado pelo tidos "normais": 


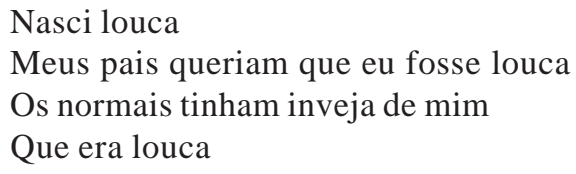

O olhar lançado ao falatório de Stela não pretende buscar uma unidade de sentido em sua fala. Concordo quando Loriga afirma que o erro mais comum cometido pelos historiadores é "enclausurar a existência [...] em busca de uma improvável unidade de sentido", o que revela "uma ingenuidade imperdoável, ainda mais porque, neste século, a literatura não se cansou de revelar a natureza descontínua e provisória do real”. Ao contrário, a fala de Stela desconstrói, reinventa a si mesma, brincando com as palavras, explorando seus significados para falar de sua realidade.

"Nasci louca”, afirma Stela, provavelmente não por concordar com o diagnóstico psiquiátrico, mas para legitimar aquilo que já sabia antes de qualquer diagnóstico e internação. Ela ressalta que "os normais" a invejavam, por ser "louca”, talvez acreditasse que tal condição a autorizava a falar aquilo que pensava, sem ponderar as conseqüências. Por um longo período na história, aos ditos loucos tudo era permitido dizer. Neste sentido, Erasmo de Rotterdam, no século XVI, na aurora da modernidade ocidental, em sua obra "Elogio da loucura", escreveu que essa "deve gozar de um grande favor no céu, pois diariamente é perdoada”. Segundo o autor, quando um homem cometia alguma tolice, "ele a atribui imediatamente à loucura, protegendo-se do castigo junto a essa boa deusa”. Esta parece ser a bricolagem de Stela, dizendo tudo o que desejava, protegida em sua loucura.

Por vezes a fala de Stela é tomada por desesperanças: "perdi o gosto o prazer o desejo a vontade o querer". Em seu falatório a personagem parece se confrontar a todo o momento com sua situação de internada, lutando todos os dias contra as mazelas presentes no cotidiano institucional:

Eu não tenho coragem de enfrentar nada

Eu tenho que enfrentar a violência

A brutalidade e a grosseria

E ir à luta pelo pão de cada dia

Stela enfrentou a "violência”, “a brutalidade e a grosseria” que por muitos anos povoou a Colônia Juliano Moreira. Seu falatório perpassa assuntos delicados, que ainda hoje surgem como tabus dentro das instituições psiquiátricas, como por exemplo, as relações sexuais entre pacientes e entre paciente e funcionários:

Tinha terra preta no chão

Um homem foi lá e disse

Deita ai no chão pra mim te foder 


\author{
Eu disse não \\ Vou me embora daqui \\ Aí eu saí de lá vim andando \\ Ainda não tinha esse prédio \\ Não tinha essa portaria \\ Não via tinta azul pelas paredes \\ A parede ainda não era pintada de tinta azul
}

A fala de Stela é áspera, desenha significados obscuros, difíceis de lidar, e certamente causará constrangimento aos leitores mais desavisados.

Eu fui agarrada quando eu estava sozinha

Não conhecia ninguém não conhecia nada

Não via ninguém não via nada

Nada de cabeças e corpos

Nada de casa nada de mundo

Eu não conhecia nada eu era ignorante

Depois que eu fui agarrada pra relação sexual e

Pra foder

Depois, só depois eu comecei a ter noção e ficar

Sabendo

Não há registros que comprovem o que Stela diz, contudo, além disso não cabe aqui buscar uma verdade oculta em suas falas e sim problematizar sua tessitura narrativa, problematizando o cotidiano institucional por ela instituído. Sua fala parece denunciar "fui agarrada pra relação sexual”. Relações sexuais, consentidas ou não, eram freqüentes dentro da Colônia Juliano Moreira e, muitas vezes, as pacientes acabavam grávidas. O destino dos

bebês que nasciam no hospício, frutos de encontros amorosos por vezes até involuntários entre internas e funcionários, eram doados para qualquer um, sem ao menos registro civil. Ou, em muitos casos, perambulavam a infância inteira pelo manicômio de mão em mão e, a qualquer manifestação de desobediência ou rebeldia, rotulados de loucos e tratados com uma brutalidade nem sonhada pela ditadura militar brasileira: choques nos seios e nas vaginas das meninas de 10, 11 e 12 anos, espancamentos, prisões e overdose de antipsicotrópicos (Cadernos Terceiro Mundo, 1992)

Apesar de não haver nenhum registro a respeito de uma possível gravidez de Stela durante o período em que esteve internada, em uma de suas falas ela diz: "Eu já produzi uma criança no colo outra no corpo / Sem eu saber que estava produzindo uma criança / Pequena”.

Stela assistiu de camarote a decadência de uma instituição construída "de forma a ser a mais perfeita e apropriada do gênero" ${ }^{10}$. Denúncias a respeito das 
precárias condições em que viviam os pacientes ganharam espaço na mídia a partir da década de 80. Em 18 de maio de 1980 o Ministério da Saúde autorizou a realização de uma reportagem na instituição. Realizada pelo jornalista Samuel Wainer Filho, exibida no programa "Fantástico", da Rede Globo, o material ajudou a apurar algumas estatísticas: a Colônia Juliano Moreira comportava 3.007 doentes, 749 funcionários (706 lotados na administração e não nos núcleos junto aos internos) e apenas 20 médicos para tratar do "batalhão". A filmagem percorreu todos os recantos da Colônia, revelando inclusive os trabalhos de outro internado, Arthur Bispo do Rosário, hoje considerado um artista genial, reconhecido internacionalmente, o qual passou 50 anos internado na Colônia Juliano Moreira (entre 1948 e 1989) $)^{11}$.

Segundo Dr. Caminha, um dos diretores da instituição ${ }^{12}$ :
A denúncia teve grande repercussão, contribuindo decisiva- mente para se dar início a um processo de transformação da Colônia, especialmente se levarmos em conta que aquele era o "lugar do silêncio", onde nenhum jornalista ou fotógrafo ja- mais conseguira penetrar. O problema foi para as ruas, e o Ministério da Saúde dirigiu-se à comunidade na busca de al- ternativas viáveis para solucioná-lo.

A data em que a reportagem foi ao ar, 18 de maio de 1980, marca o dia da Luta Antimanicomial, movimento preocupado em melhorar as condições de vida dentro dos manicômios. Foi a partir daí que se iniciaram significativas mudanças na Colônia Juliano Moreira:

o ano de 1980 foi uma revolução no hospício de Jacarepaguá. A Colônia deixaria de ser uma estação de fim de linha na carreira dos alienados. Funcionários, sob a nova ordem, giraram chaves, abriram fechaduras, arrancaram as portas das celas [...]. Era o fim dos quartos-fortes, solitárias [...]. Os eletrochoques foram proibidos ${ }^{13}$.

A personagem que apresentei ao leitor acompanhou a todas estas mudanças. Conforme Aquino: "Stela do Patrocínio pôde se beneficiar desde movimento que denominamos Reforma Psiquiátrica. A sua fala passou a não ser mais lida como delírio, nem seus escritos banalizados como excentricidades” ${ }^{\text {. }}$. Foi uma sobrevivente em meio a inibição da subjetividade e da individualidade, características que por muitos anos perpassaram a assistência psiquiátrica no mundo inteiro. Desta forma, sua fala, redigida em forma de textos, representa a sua forma de resistir à homogeneidade institucional. 
"Estar internada é ficar o dia todo presa": o cotidiano no falatório autobiográfico de Stela do

149

Patrocínio

\section{CONSIDERAÇÕES FINAIS}

Stela do Patrocínio pertence "àqueles milhões de existências que estão destinadas a não deixar rastro" ${ }^{15}$, excluída, esquecida, varrida da história por uma internação de três décadas. Através de seu falatório, a vida cotidiana na instituição "é trazida à luz como um modo de existência em que o indivíduo cria relações na base de sua própria possibilidade de ação" ${ }^{16}$. Ela agiu, não se calou, jogou com sua única possibilidade de ação diante dos limites institucionais: a sua fala, permeada por perplexidade, indignação e sem duvida, muita lucidez.

Neste artigo pretendeu-se analisar a trama narrativa desta singular personagem, problematizando suas percepções a respeito de si, percebendo como estas se entrelaçam à imagem por ela instituída a respeito do cotidiano institucional. De acordo com Loriga, a instituição exila o indivíduo da verdadeira vida, acabando por destruí-lo ${ }^{17}$. Creio o falatório poético de Stela mostra que, mesmo diante de tais limitações, é possível manter a singularidade, resistindo ao sentido habitual atribuído às trajetórias daqueles tidos como loucos.

\section{NOTAS}

2 Refiro-me a pesquisa realizada em função de minha tese de doutorado, "Do esquecimento do tombamento: a batalha discursiva sobre Arthur Bispo do Rosário" (1909 - 1989). Tese (Doutorado em História). UFRGS: Porto Alegre, 2010.

${ }^{3}$ MOSÉ, Viviane (org.). Stela do Patrocínio Reino dos bichos e dos animais é o meu nome. Rio de Janeiro: azougue editorial, 200 I, p. 21.

${ }^{4}$ MOSÉ, Viviane. Op. cit., p. 20.

${ }^{5}$ Todas as citações referentes à fala de Stella presentes neste artigo tiveram como fonte o livro organizado por Mosé.

${ }^{6}$ PETERSEN, Silvia. O cotidiano como objeto teórico ou o impasse entre ciência e senso comum no conhecimento da vida cotidiana. In: MESQUITA, Zilá e BRANDÃO, Carlos Rodrigues (org.). Territórios do cotidiano, uma introdução a novos olhares e experiências. Porto Alegre: Ed. UFRGS/EDUNISC, 1995, p. 60.

${ }^{7}$ PETERSEN, Silvia. Op. cit., p. 59.

${ }^{8} \mathrm{O}$ referido documentário realizado em 1982

9 LORIGA, Sabina. "A biografia como problema". In: REVEL, Jacques (org.). Jogos de escalas: a experiência da microanálise. Rio de Janeiro: Editora da Fundação Getulio Vargas, 1998, p. 246.

${ }^{10}$ A construção da Colônia Juliano Moreira, assim como ocorreu com outras colônias brasileiras, atendeu às propostas que procuravam alternativas aos asilos fechados, surgidas no Brasil na segunda metade do século XIX. Com sua criação, pretendia-se resolver o problema da superlotação do Hospício Nacional, além de substituir as decadentes Colônias da Ilha do Governador. AMARANTE, Paulo. Psiquiatria social e colônias e alienados no Brasil ( 830 - 1920). Dissertação (Mestrado em Medicina Social), Universidade do Estado do Rio de Janeiro, UERJ, Rio de Janeiro, 1982, p. 8.

" Arthur Bispo do Rosário acreditava ter sido incumbido por Deus de recriar o universo, realizando esta missão com a sucata encontrada na instituição. Criou assim um labirinto onde poucos podiam penetrar, composto por 802 peças, hoje tombadas pelo Instituto Estadual do Patrimônio Artístico e 
150 REVISTA ESBOÇOS Volume 16, № 22, pp. 139-151 - UFSC

Cultural. Suas criações representaram o Brasil na Bienal de Veneza em 1992 e ocuparam importantes espaços destinados às obras-primas da arte ocidental, como o Jeu du Paume de Paris.

${ }^{12}$ Apud SILVA, Jorge Anthonio. Arthur Bispo do Rosário. Tese (Doutorado em Comunicação e Semiótica), São Paulo, PUC/SP, 1997, p. 166.

${ }^{13}$ HIDALGO, Luciana. Arthur Bispo do Rosário - O senhor do labirinto. Rio de Janeiro: Rocco, 1996, p. 124.

14 MOSÉ, Viviane (org.). op. cit. p. 15.

${ }^{15}$ FOUCAULT, Michel. Vigiar e Punir. História da violência nas prisões. Rio de Janeiro: Ed. Vozes, 2002, p. 96.

${ }^{16}$ PETERSEN, Silvia. Op. cit., p. 60.

${ }^{17}$ LORIGA, Sabina. Soldats. Um laboratoire disciplinaire: I'armée piémontaise au XVIII e siècle. Paris: Mentha, |99|, p. II. 